\title{
Profile 017
}

East (Gränna)

$25 \mathrm{~m}$

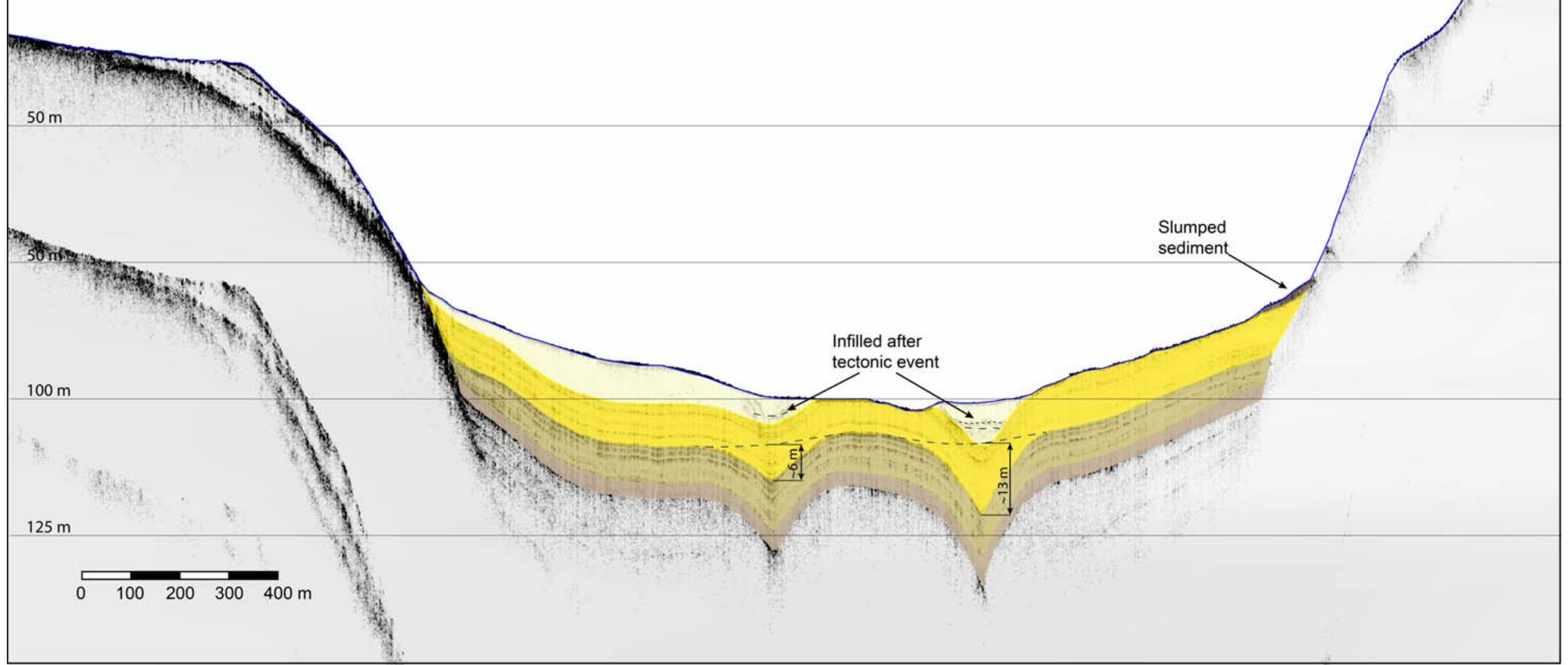

Figure DR1. Chirp sonar profile crossing the deep strait between the mainland (East) and the island Visingsö (West). The sediment unit deposited after the Earthquake is shown with a light yellow color. Estimated vertical displacements based on the sediment structures are shown on the figure. 


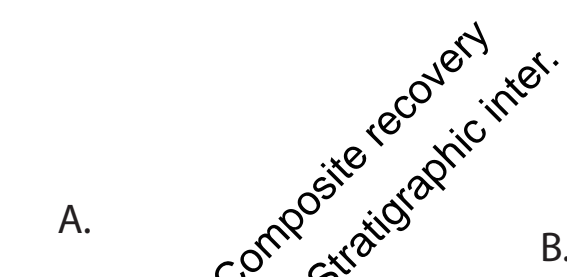

B. Vat12-A3-2, 24-35cm (7.99-8.11 mblf)

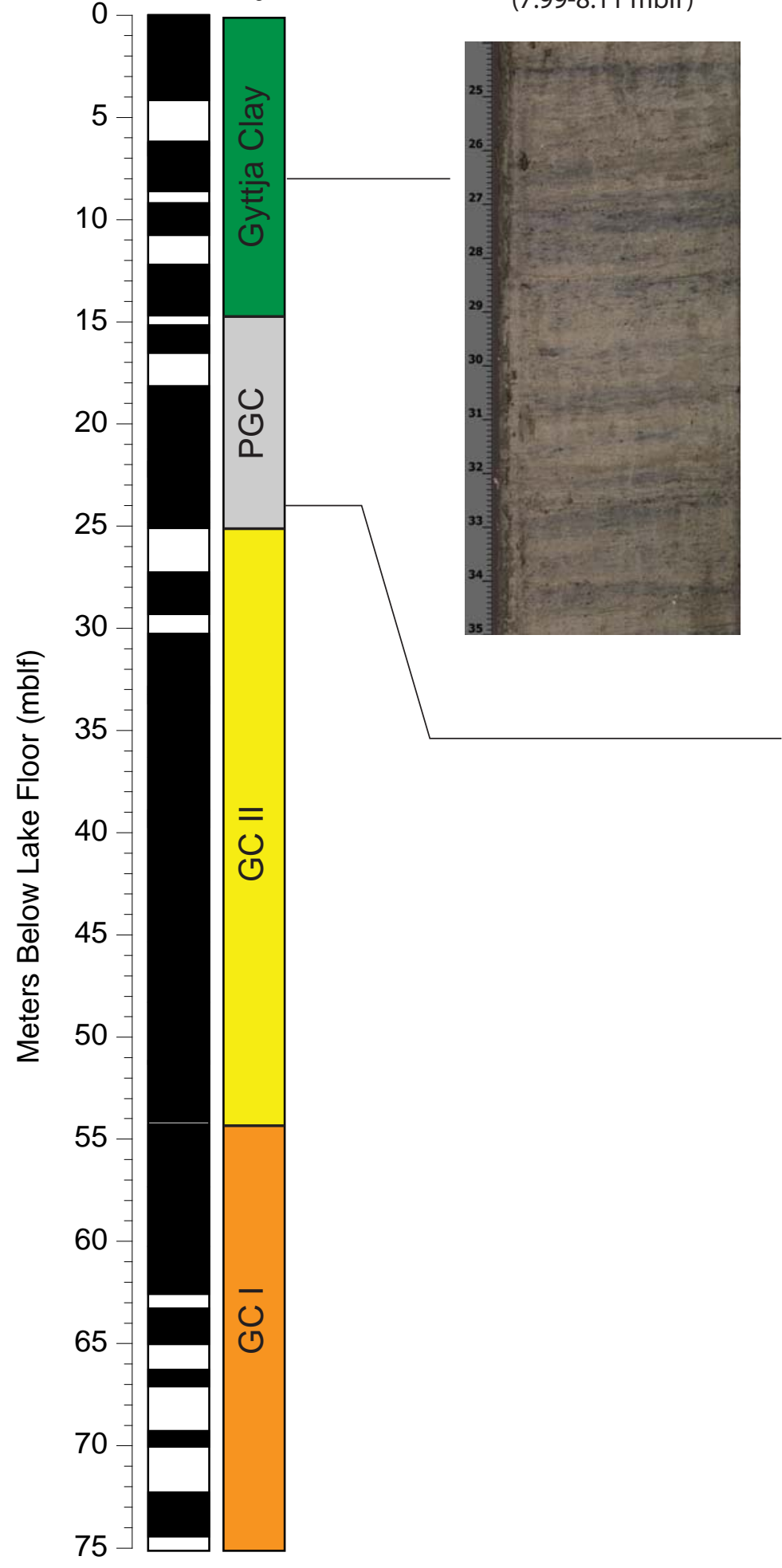

C. Vat12-E10-1, 220-245 cm

(23.45-23.70 mblf)

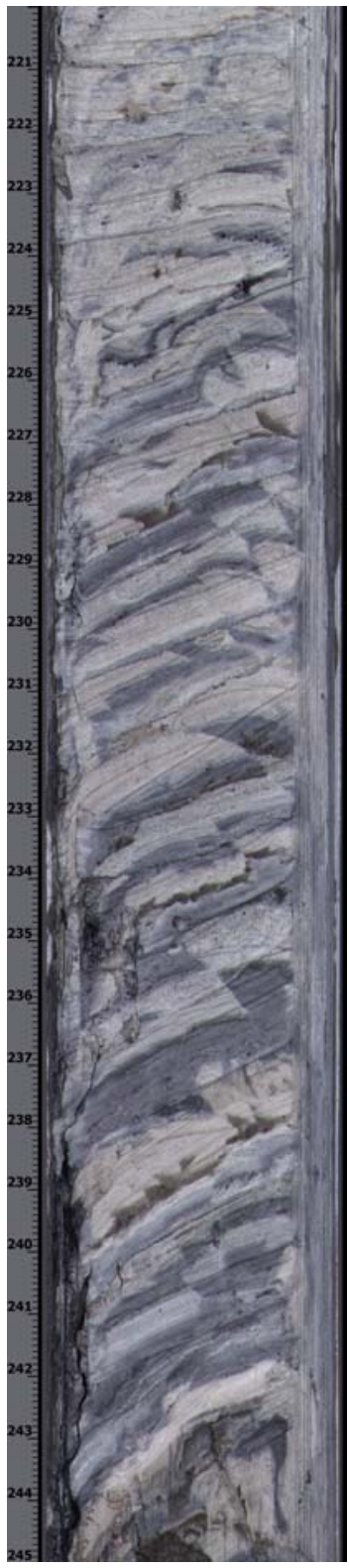

Vat12-D2-1, 46-76 cm, (22.28 - $22.58 \mathrm{mblf})$

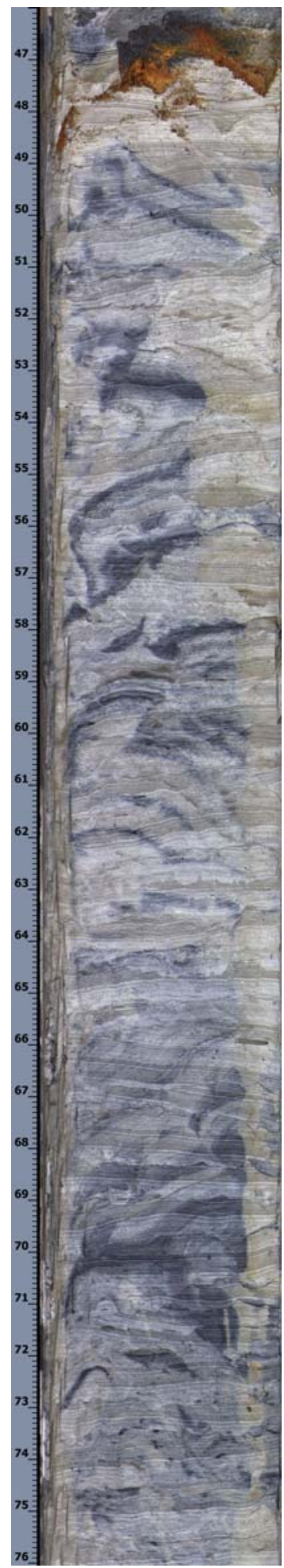

Supplementary Figure DR2. Seismically induced faulting and deformation in sediments from Southern Lake Vattern. A. Cummulative core recovery from 5 boreholes drilled in soutern Lake Vattern. Interpretation of the stratigraphic units shows the boundaries between glacy clay (GC), Post glacial clay (PGC) and Gyttja clay. B. Image of a typcial undistrubed interval of gyttja clay recovered from Hole A. C. Extensive faulting and core disturbances at the base of the Post Glacial Clay unit. Similar levels of distrubance are observed in cores from adjacent boreholes (Holes D and E) indicating that drilling distrubances are not responsible for the obsrved deformations. Reverse microfaults and folding of sediments are evident in both sections. 


\section{Figure DR3}

High-resolution image of text Figure 3. A: Seismic reflection profile $A-A^{\prime}$ across graben in southern part of Lake Vättern. B: Subbottom profile B-B' (TWT-two-way traveltime). C: Enlargement of B, with location of drilling site marked in profiles. Major stratigraphic boundaries are inserted (GC II-glacial clay unit II; GC — glacial clay unit I; PGC - postglacial clay; GC - gyttja clay). Locations of profiles are shown in Figure 1 of the main article.

\section{Figure DR4}

High-resolution image of text Figure 4. Sub-bottom profiles across Lake Vättern graben. A,B: Profile C-C' east of island of Visingsö. C,D: Profile D-D' near island of Jungfrun in northern part of study area. Locations of profiles are shown in Figure 1 of the main article. Estimation of vertical displacement is inferred in B and D. 
Figure DR3

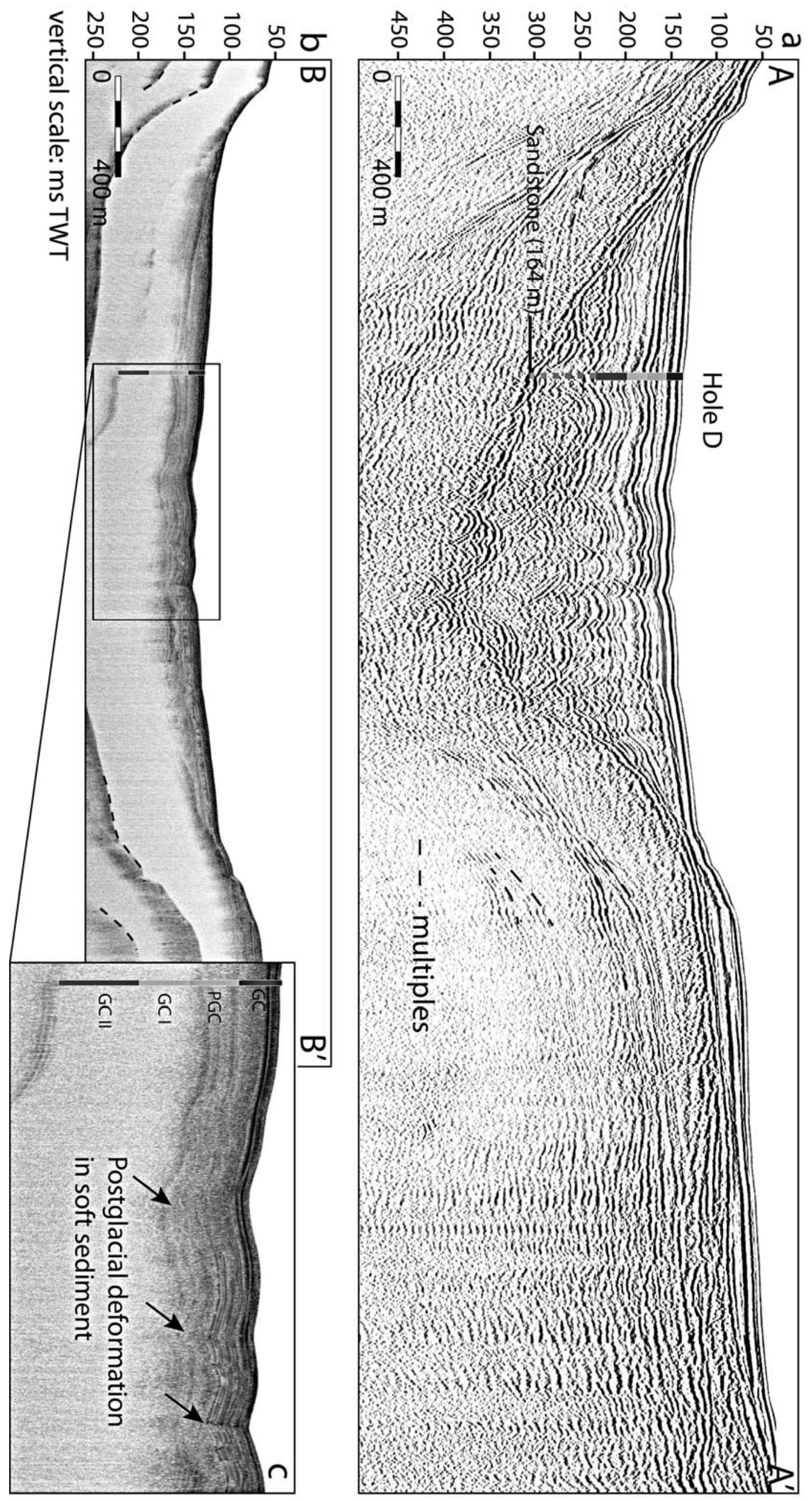


Figure DR4

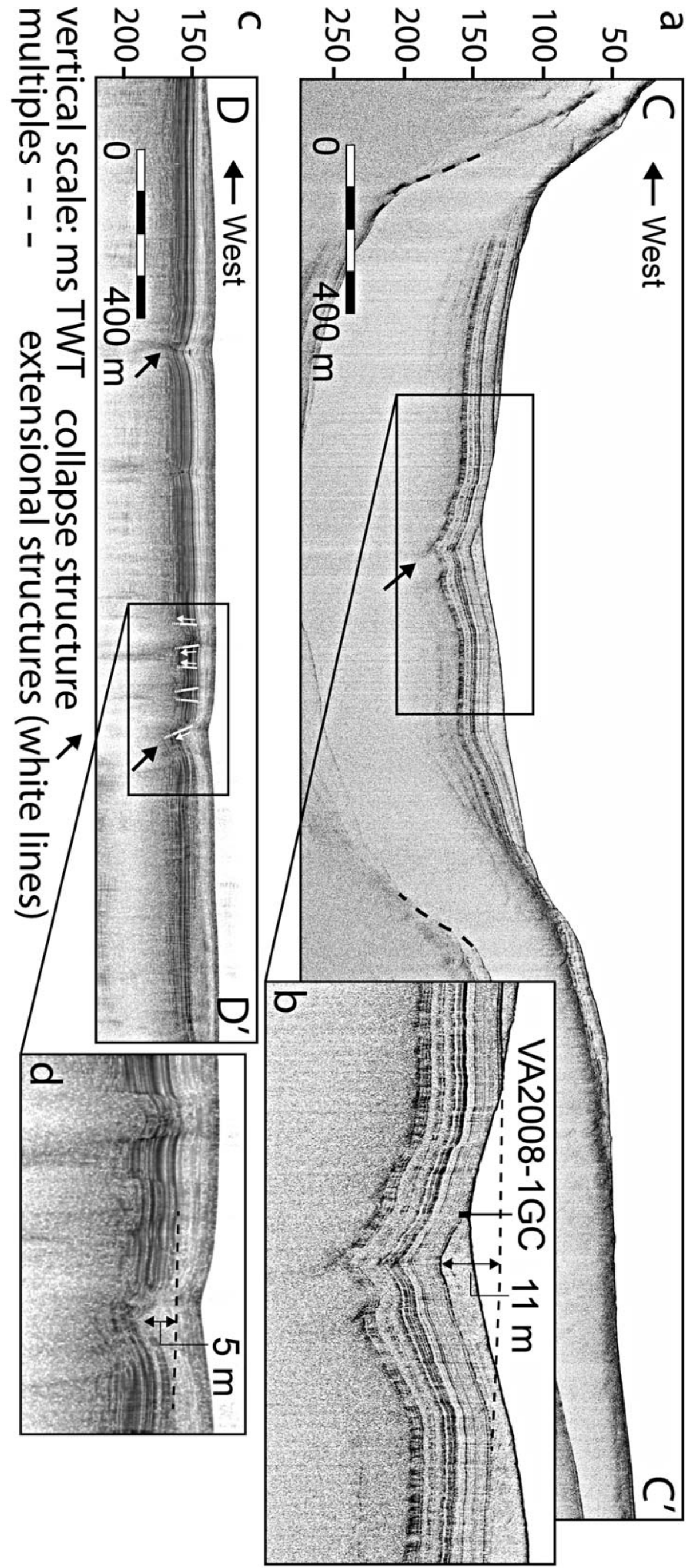

